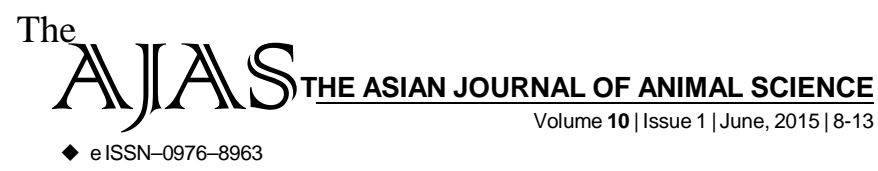

RESEARCH ARTICLE........

\title{
Histopathological alterations of profenofos on the ovary of the fresh water air-breathing fish Channa gachua
}

\author{
ANAMIKA, RANJANA AND A.P. MISHRA
}

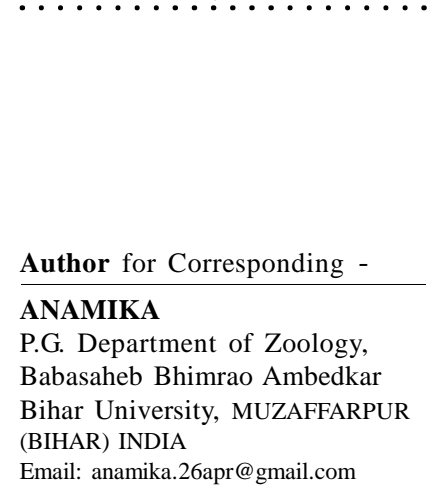

Email: anamika.26apr@gmail.com

See end of the article for

Coopted authors'
ABSTRACT...... The present study is aimed to assess the histopathological impact of lethal $(0.3 \mathrm{ppm})$ and sub lethal $(0.06 \mathrm{ppm})$ concentrations of profenofos in the ovary of an air breathing fresh water teleost Channa gachua. Reduced size of mature oocytes, vacuolation in cytoplasm, damaged ovarian follicles, increase in inter-follicular space, breaking of ovarian wall, occurrence of necrosis, damaged structure of ovarian follicles, formation of fragmented ova and atretic oocytes and extrusion of karyoplasms was observed in mature oocytes.

KEY WORDS...... Profenofos, Histopathology, Channa gachua, Ovary

HOW TO CITE THIS ARTICLE - Anamika, Ranjana and Mishra, A.P. (2015). Histopathological alterations of profenofos on the ovary of the fresh water air-breathing fish Channa gachua. Asian J. Animal Sci., 10(1) : 8-13.

ARTICLE CHRONICLE - Received : 28.01.2015; Revised : 07.04.2015; Accepted : 20.04.2015 